http://dx.doi.org/10.4314/gjl.v4i2.1

\title{
THE MULTIPLE SENSES OF Sつ IN SIGU
}

\author{
Jonathan Allen Brindle
}

\begin{abstract}
In Sigu, a previously unrecorded non-natural, secret, and sacred language, the high frequency and meaning variation of the verb so are among the notable aspects of the language. The paper outlines the nature and distribution of the phenomenon using a lexical-translational approach and presents the different usage values of the verb. It then investigates the meanings of so, and how its usage values are related. The analysis proposes that $\boldsymbol{s o}$ is lexically underspecified and that linguistic and non-linguistic strategies work to narrow down the range of possible meanings.
\end{abstract}

Key words: lexical manipulation, lexical semantics, underspecification, alternate language

\section{Résumé}

La fréquence élevée et l'éventail des emplois du verbe so sont parmi les aspects notables du Sigu, une pseudo-langue non-documentée jusqu'à présent. Cet article expose la nature et la distribution du verbe so en utilisant une approche lexico-traductionnelle et présente les différents emplois de ce verbe. Ensuite, il examine les significations de so et les liens entre ses valeurs d'emploi. L'article propose que so est sous-spécifié dans sa représentation lexicale, et que des stratégies linguistiques et non-linguistiques ont pour rôle de limiter l'éventail de ses significations possibles.

\section{Preliminary ${ }^{1}$}

\subsection{What is Sigu?}

Sigu is a non-natural, secret, and sacred language 'owned' by a clan of ethnic Chakali that lives in Gurumbele, a village in Ghana's Upper West Region. ${ }^{2}$ It is non-

\footnotetext{
${ }^{1}$ Acknowledgement: Thanks to Rachel Selbach, Kaja Borthen, and Christy Cheronne Ringrose for reading the manuscript and for their helpful comments. Special thanks to Amoa Spenter Bari Naa and Awie Bakuri Ahmed who, each in their own way, have made substantial contributions to my kowledge of Sigu.
} 
natural in the sense that it has no native speakers. The language is 'secret' and 'sacred' because local protocols protect its transmission and usage, and spiritual endowment is believed to be given by the shrine and its related medicine. It is mainly sung, only seldom spoken, and preserved orally, transmission taking place in rites of initiation, blood sacrifices, annual performances, and funerals of group members. Small talk among the initiates has been observed but it is not clear what role it plays in learning: it must be considerable, but it was observed to be quite infrequent. ${ }^{3}$ The amount of exposure to the language is manifestly limited, thus becoming a professional singer involves attending many events and getting the chance to perform. Recordings, either on cassettes or memory cards, are also likely to play a role in learning, but only a handful of people have access to them. Because it is tied to specific, occasional, and, for the most part, unpredictable events, Sigu is not a learnerfriendly language. In terms of the exposure to the language and the potential for language learning, Sigu's usage cannot be compared with normal communication.

\subsection{What type of linguistic system is Sigu?}

If natural languages are defined as languages which spontaneously evolve in the mind of children and are not planned beforehand, then Sigu is not a natural language. ${ }^{4}$ Sigu is not used in everyday communication, so it is not a code to which children are constantly exposed. Its history is unknown and attempts to demonstrate genealogical affiliation to other languages of the area have failed. Sigu may have been designed and planned, yet today's speakers and owners explicitly attempt to keep the language as it has been passed down to them. The conjecture is that all constructed

\footnotetext{
2 The information in this section is based on observations from fieldwork in the Chakali area from 2008 until today. By 'owned', I mean that the clan is in charge of the initiation rite which defines users' rights. Sigu shows almost no linguistic similarities to the secret language of the Dogon of Sanga, which Leiris transcribed as sigui, sigi, sigu, and sugu (Leiris 1948: 485). This is not a surprising coincidence. That the two peoples share cultural features is ostensible when one read the available work on Dogon masking- and initiation traditions. Further, there is a definite shared masking culture in this NorthSouth stretch, the awa of the Dogon to the north (ibid: 435), the koro of the Bobo in south-west Burkina Faso (Le Moal 1980:168), and the sigmaa of the Chakali, Vagala, Tampulma, and others in the South. When necessary each language is preceded by cli. for Chakali and sig. for Sigu.

${ }^{3}$ The actual Sigu term for 'initiated' is gàràbj̀yó, which refers to someone who has 'converted' to the shrine Dààbàytólúgú through initiation. The person is bound to all the doctrines of the shrine. The term is also translated in Chakali as níhĩ $\tilde{\tilde{\varepsilon}}$ 'elder' since initiation endows a person with knowledge equal to that acquired through a long life. Although there are good reasons to believe that several grades may have operated in the past, today all newly initiated individuals have the same grade as anyone else.

${ }^{4}$ I avoid using the expression 'artificial language' because all constructed languages may be seen as 'natural' as they are essentially the product of human cognition. Perhaps the notion of being 'planned' and 'non-spontaneous' may legitimise the term 'artificial', but in practice this may also be problematic given, for example, the proficiency of Esperanto and the fact that the language has native speakers.
} 
languages have features of natural languages by the very nature of the designers. Without a posited time depth for the spiritual group that uses Sigu, and the process by which it got to its present state, it is more appropriate to say that Sigu displays 'Chakalic' features. The term 'Chakalic' suggests a linguistic appearance of Sigu without necessarily stipulating an origin.

At first sight, Sigu is a lexically-manipulated L1 (in the sense of Mous 2003: 209). Chakali, a Southwestern Grusi language (Gur, Niger-Congo), is the first language of the singers. Many features found in Chakali are also found in Sigu: the word order, phrase and word formations, phoneme inventories, and syllable structures of Sigu and Chakali are identical. The personal pronouns are also identical, except for a mismatch in first and second person plural. Nonetheless, unlike a prototypical lexically-manipulated language, Sigu is lexically and grammatically much 'leaner' than Chakali. The lexicon appears to be small, probably due to the limited domain of application and limited diversity of experience. Nominal inflection and derivation are rare. When a plural is made, the suffix $-s V$ is identical to one of the three plural markers of Chakali. Still, the most striking difference between Chakali and Sigu is the near absence of grammatical particles. Sigu does not have the tenses, aspects, moods, demonstratives, and various other particles that Chakali makes use of. Only one preverbal particle, i.e. nI, whose meaning is not yet fully understood, is attested. Therefore Sigu cannot be classified as a lexically-manipulated L1 - nor an argot-type of alternate language in the sense of Bagemihl (1988: 17) or a pseudo-langue in the sense of Moñino (1991) - since it cannot be defined solely on the basis of vocabulary replacement.

Although case studies exist, lexically-manipulated languages have not received much attention, because they "simply involve a vocabulary (lexicon) which is distinct from the ordinary language" (Bagemihl 1996: 698) and are "usually not predictable" (Laycock 1972: 63). While ludling (essentially phonological manipulation, see Laycock 1972: 61) has contributed substantially to linguistic theories by providing secondary evidence which support such issues as the skeletal tier of auto-segmental phonology (McCarthy 1991), the establishment of licit syllable types of the source language (Hombert 1986: 176), the autonomy of tones (Demolin 1991: 45), among others, a series of questions remains when dealing with lexicallymanipulated languages. I believe that a study of the verb so in Sigu addresses some of these questions.

While the method of concealment in the case of ludling can be reduced to predictable and regular (morpho-) phonological rule(s) affecting the source language's phonological representation without affecting the semantics, in the case of lexically-manipulated languages, concealment strategies are generally non-systematic and affect different aspects of the lexical items. Such phenomena could be explained 
with relexification (Muysken 1981, Lefebvre 1988, Wittman \& Fournier 1996, Lefebvre 2014), paralexification (Mous 2001), or Full Transfer/Full Access (Schwartz \& Sprouse 1996), among others, that is, theories dealing with the representation of vocabulary alternation or replacement. If any of these hypotheses is correct - so that, roughly speaking, the grammar of Chakali is the grammar matrix of Sigu, plus relabeling ${ }^{5}$ - then one question is: are the verbal lexemes of the matrix language copied into the alternate language one-to-one? In other words, is each lexical entry assigned a new label? The analysis put forward in this article shows that it is not necessary for an alternate language to map lexical items one-to-one because verb meanings are built incrementally from the activation of certain semantic representations and contextual enrichment. The article is organised as follows: in $\S 2$ the method and dataset are explained and selected examples are presented, in $\S 3$ an analysis of $\mathbf{s o}$ is proposed, and finally in the conclusion I suggest how the findings can contribute to further research on lexically-manipulated languages. One of the contributions of this paper is to simulate the sort of (non-) linguistic knowledge required to succeed in interpreting an ambiguous verb in an alternate language.

\section{The Multiple Senses of the Verb so}

\subsection{Method and Dataset}

Although there are singers whose first language is not Chakali, all singers and consultants I have worked with are from Ducie and Gurumbele, two of the four remaining villages where Chakali is spoken by the majority. The linguistic landscape has changed in the last 50 years, but it is fairly accurate to say that today Chakali speakers have Waali (Western Oti-Volta), Tampulma, Pasaale, or Vagla (all Southwestern Grusi languages), as well as varieties of Akan if they have worked in the south of the country, in their linguistic repertoire. Most members of the spiritual group, especially the older generation, have not been to school and do not understand English. However a few do, and could help with transcription and translation. The bulk of the work was carried out with two male consultants (both in their 30s), native speakers of Chakali, fluent in Waali and Ghanaian English, as well as being Sigu enthusiasts and who also perform. The transcription is based on slow repetition of the lyrics. The orthography is a mixture of phonetic and phonemic transcription and the use of diacritics represents an impressionistic representation of intonation. ${ }^{6}$ Other consultants have provided occasional clarifications on transcriptions and translations.

\footnotetext{
5 "Relabeling is a mental operation that consists in assigning a lexical entry of a given language, $\mathrm{L}_{1}$, a new label taken from another language, $\mathrm{L}_{2}$." (Lefebvre 2014: 9)

6 It is important to mention such details because the reader may believe that lexical or grammatical tones can affect the interpretation. The form under study does not contrast tonemically.
} 
Specific questions were normally addressed directly to the performers. Eleven songs have received a narrow annotation, that is a phonetic transcription, a translation in Chakali and English, an interlinearisation, and comments either from the consultants involved in the transcription-translation process or from the performers. A parallel corpus was created using the Chakali and English translations. ${ }^{7}$ Table 1 displays the tokens in a descending order according to their frequencies.

Table 1: Frequency list

\begin{tabular}{lll}
\hline Form & Glosses & Tokens in text \\
\hline$s o$ & (several analyses) $v$. & 481 \\
$n I$ & pre-verbal particle & 314 \\
$a$ & 3.PL.-H|3.SG.IPRS pro., conn. & 298 \\
$\sigma$ & 3.SG pro. & 233 \\
$n$ & 1.SG pro. & 132 \\
danI & OBJ.CLS pro. & 130 \\
$I$ & 2.SG pro. & 128 \\
loma & house $n$. & 124 \\
\hline
\end{tabular}

The frequency list in Table 1 contains fairly common top-listed words of corpora, at least corpora of isolating languages for which frequency lists have been compiled. It is normal, if not a rule, to find pronouns, connectives, determiners, auxiliaries, and adpositions on top of such lists. Still, it is unexpected to find a verb topping a frequency list, and as we will see later, so cannot function as a preverb or auxiliary. This fact is intriguing: how can a verb surpass all other items in a frequency list, and what is the function and meaning of that verb?

\subsection{Lexical-translational Heuristic to Sense Identification}

In a lexical-translational approach to sense discovery, the process of finding meanings relies on corresponding translations. ${ }^{8}$ The first step is to identify the occurrences of the verb so in the parallel corpus, extract the senses of their Chakali translations and cluster them into groups. This is what Table 2 attempts to show.

The tentative subdivisions take into account the sort of event described by the Chakali predicates. The groups existential, possessive, motion and transfer are

\footnotetext{
7 The parallel corpus consists of approximately 1600 sentences, 5400 word tokens, and 650 word types.

${ }^{8}$ An alternative method for the analysis of the data at hand is developed in Dixon (1971).
} 
subjective and pre-theoretical eventuality group labels used in the categorisation of verbal predicates. Since the goal is not to provide an articulated representation of verb classes in Chakali, these four groups were deemed appropriate for the exercise at hand. In addition, the goal is to account for the sense groups, not for each Chakali verb so was translated into. In \$2.2.1 to \$2.2.4, examples are given where the verb so is translated with various Chakali verbs. The glossing of the Sigu verb is based on the English translation of the Chakali verb. A predicate-argument structure is also provided at the bottom of each example. Again these structures are not analytic but descriptive, isolating the predicate and the realisation of its arguments.

Table 2: Preliminary categorisation of the different senses of the Sigu verb so based on Chakali translations

\begin{tabular}{|c|c|}
\hline Sense group & Usage value in Chakali (tokens) \\
\hline Existential & 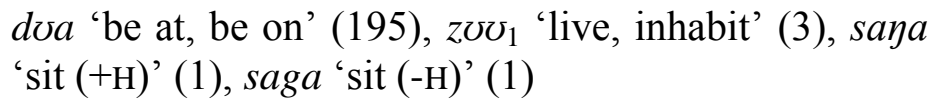 \\
\hline Possessive & kpaga 'have' (24) \\
\hline Transfer & 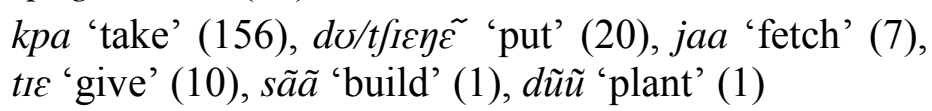 \\
\hline Motion & 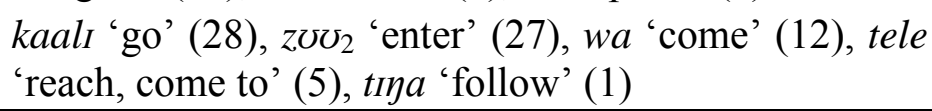 \\
\hline
\end{tabular}

\subsubsection{Existential-locative}

The verb so can depict various existential-locative relations expressing the existence of something at some place. While Chakali makes fine distinctions based on semantic restriction requirements (Brindle 2011, Brindle and Atintono 2012), so is translated into Chakali's existential-locative predicate dwa 'be at, be on' in (1a), zwठ 'live, inhabit' in (1b), postural predicate saya 'sit' (with +HUMAN subject nominal) in (1c), and saga 'sit' (with - HUMAN subject nominal) in (1d). ${ }^{9}$

\footnotetext{
${ }^{9}$ The reference in the parentheses provides the name of the song and the line number in the corpus. From the first interlinearisation tier, each example provides a Sigu sentence, a gloss, the Chakali translation, an English translation, and a predicate-argument structure. The abbreviations are: OBJ.CLS object pronoun classifier, PV pre-verb particle, INTS intensifier, CONN connective particle, $+/-\mathrm{H}$ human gender value, and QUANT quantifier.
} 


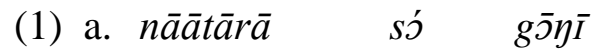

human.being be.at road

'(di) nàr dóá tìwíí ní'

'(That) someone is on the road'

(AMO-KOT-KK 1.31)

so (human, road)

b. dááré̉wóy s̄̄ náyvòlì

salt be.in soup

'jìsá kà zơừ dìsá ní'

'Salt is in the soup'

(AMO-NME 1.291)

so (salt, soup)

c. kùntùykpáleḿá pəúá sò tàyì á zànnáárì dààrèywòy

bird ass sit land CONN see Salt

'kùntùykpálémá já sànà káá jìnè jìsá'

'Bird sits while watching Salt'

(AMO-NME 1.204)

so (buttocks, ground)

d. póná̃vìlúù sò nání

ass.excrement be.on back

'bíná ságá hàbòà ní'

'Faeces are on the back'

(AMO-SUN 1.141)

so (faeces, dorsum)

In (1) so is translated into an existential-locative predicate with two arguments, one the entity to be located and the other the location of that entity. Note that Sigu has the verb bos 'be' which consistently translates into Chakali jaa in equational and predicational structures.

\subsubsection{Possessive}

The verb so is translated into the Chakali possessive predicate kpaga 'have'. The relation between the possessor and the possessed, and the characteristics of the two arguments, are described as follows: in (2a) the possessed is an unowned possession and a physical quality of the possessor, i.e. as in English 'forest has animals', in (2b) the possessed is an associated quality of the possessor, and in (2c) the possessed is an owned possession. ${ }^{10}$

10 In (2a), the possessed entity is conceptualised as +HUMAN, indicated by the 3.PL.+H pronoun ba 'they', while the Chakali translation analysed 'land creature' as -HUMAN with the 3.PL. - H pronoun a 'they'. This example also demonstrates that, unlike Chakali, so does not phonologically absorb object 
(2) a. tání sò bà dání

land have 3.PL OBJ.CLS

'hàylí́ kpágāā wà'

'There are land creatures' (lit. land has them)

(AMO-FAR 1.6)

so (land, creature)

b. à mùngú kpálám só sō̄̄ndēȳ

3.PL INTS QUANT.all have name

'àmùn né kpágá sóná'

'They all have names'

(AMO-FAR 1.155)

so (thing, name)

c. nāātārā yménćfià̀̀ bòní só vūūrī

human.being one NEG have medicine

'nìdígímáyá wàà kpágà lúlií'

'Medicine does not belong to one person'

(AMO-SUN 1.102)

so (human, medicine)

In summary, so in (2) translates into a possessive predicate with two arguments, one being the possessor and the other the possessed.

\subsubsection{Motion}

Motion events can also be conveyed by the verb so. All the examples in (3) express a motion towards a goal, except (3a) which conveys a movement from a source towards the deictic centre (cli. wa) and an act of going out of a location (cli. liI). In (3b) an animate agent enters a location (cli. zov), and in (3c) the agent is seen as moving away from the deictic centre to a location. Translation tokens with Chakali kaalı 'go' are appreciable considering the existence of Sigu leqgala 'go', which is the primary equivalent of the Chakali verb. The word goyı 'path, road' in (3d) is translated into Chakali tıwIIvalı 'journey', hence the occurrence of a non-agentive argument is licit. Here it means a voyage into the ancestors' world: an elderly person has died, and the ancestorship journey has come. In (3), so is translated into Chakali motion predicates taking two arguments; an entity and a location.

pronouns. That may be due to the particular form object pronouns take in Sigu. Object pronouns in Sigu are phrasal; they obligatorily take the form of a pronoun followed by dani or dima, labelled object pronoun classifier (OBJ.CLS), for a lack of a better term. 
(3) a. súggúrúmá só kpàntàl

tortoise come outside

'kpààkpúrò wà lìì gántál'

'Tortoise came outside (from inside a hole)'

so (tortoise, outside)

(AMO-SUN 1.151)

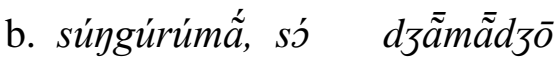

tortoise enter hole

'kpààkpúrò, zờù à bơó'

'Tortoise, (you) enter the hole'

(AMO-SUN 1.124)

so (tortoise, hole)

c. ì ní sò gónî́ú

2.SG PV go road.far

'dì ì̀ káálí tìwíi bùòlîì'

'If you go on a long journey'

so (human, road)

(AMO-SACR 1.32)

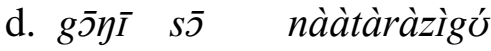

road reach elder

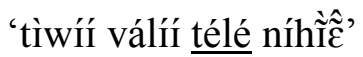

'An elder is about to die'

so (road, human)

(KPE-NME 1.128)

\subsubsection{Transfer}

Verbs of manipulation, verbs of contact and control, and verbs of transfer of possession are also used to translate so. Least commonly, the verb so translates into the 'take'-verb kpa and occur on its own, as example (4) shows.

$$
\begin{aligned}
& \text { Í s̀̀ wówòg } \\
& \text { 2.SG take money } \\
& \text { 'Í kpá mòlèbíé' } \\
& \text { 'You shall take money' } \\
& \text { so (human, money) }
\end{aligned}
$$

Crucially, however, it is observed that when so is translated into a form that has a transfer sense, it is mainly found in $\mathrm{v}_{1}$ position of serial verb constructions. ${ }^{11}$

\footnotetext{
${ }^{11}$ Lefebvre (1991) gives an account of manipulative serial verb construction in Fon (Gbe). It is striking that in Fon a verb with the form so behaves in practically the same way as the one described in this section. According to Lefebvre, so, which she translates as 'take', belongs to a closed-class of verbs
} 
These serial verb constructions correspond to what Ameka \& Essegbey (2006: 378) call manipulative serial verb construction, which is a type of serial verb construction that expresses a transfer of possession or information. In Sigu and Chakali, it normally consists of a subject, a 'take'-verb (i.e. sig. so and cli. kpa), its object, which is the thing being manipulated, followed by another verb and its object. The prototypical sequence and examples are found in (5).

(5) $\mathrm{NP} \mathrm{v}_{1[\text { take] }} \mathrm{NP} \mathrm{v}_{2} \mathrm{NP}$

a. ú sò kádáásípólà méyì j̀ kóyù

3.SG take knife cut 1.SG head

'Ú kpá kìsíè ymènà ǹ núù'

'He will take a knife to cut my head'

(AMO-SUN 1.18)

so (human, knife)

b. ¿̀ sò súngúrúmã́ síálí tàyà

3.SG take tortoise throw land

'ù kpá kpààkpúrò à jùò hàylíí nî'

'He threw tortoise away'

so (human, tortoise)

(AMO-SUN 1.79)

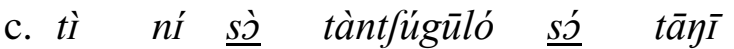

1.SG PV take guinea.corn be.at land

'dì jà wá dứú mî̃ấ'

'When we sow guinea corn'

so (humans, grains), so (grains, soil)

(FUS-SAN 1.122)

The sentence in (5a) conveys that an agent will cut someone with an instrument. The theme argument 'knife' is the instrument in the event and the agent manipulates it. The subject and object of $\mathbf{s o}$ in $\mathbf{v}_{1}$ may be seen as both acting in the event represented by the verb meyĩ in v2 position. In (5b) the object of so is not an instrument but the entity being thrown by the subject. In (5b) the serial verb construction is translated in Chakali with an overt connective a 'and', resulting in a coordinated clause with a subject overtly expressed only once, before $\mathrm{v}_{1}$. In (5c) the serial verb construction is predicated by two so verbs but is translated in Chakali with

used in serial verb constructions and co-occurs with verbs of open class. In her analysis so introduces a CAUSE predicate and an agent argument. Only motion verbs and transfer verbs occur with closed-class so. See Amberber (1995) for an alternative approach to the same phenomenon. Otherwise, until there is further evidence, I suspect that the form/sense correspondence is a coincidence. Fon and Chakali are not in contact and manipulative serial verb constructions are found in many languages of West Africa. 
the single verb dũũ 'sow' and its object mĩã, i.e. dũũ mĩã 'sow guinea corn'. In (5ac) the final argument is a location, i.e. the destination of the knife in (5a), the destination of the tortoise in (5b), and the destination of the guinea corn in (5c). All the examples in (5) contain three arguments, two of which seem to be related to $s \boldsymbol{s}$ in $\mathrm{v}_{1}$ position and one shared by two verbs.

When so translates into a Chakali 'take'-verb and functions as the only verb in a clause, that clause is very often part of a clause chain. A clause chain is defined for our purpose as clauses denoting separate events, lacking overt subject, and linked by a connective. Several instances of $\boldsymbol{s} \boldsymbol{s}$ can be found in clause chaining.

$$
\begin{aligned}
& \text { sáywárá zàyàsáyá, à șò wáálí, à șj kpálínkpàhá, } \\
& \text { bird.type stand.up CONN fetch water CONN go farm } \\
& \text { à sò tjôytfúgúló à nùgùmè tfôytfúgúló, } \\
& \text { CONN take guinea.corn CONN eat guinea.corn } \\
& \text { s̀̀yú tí } \\
& \text { abdomen be.satisfy } \\
& \text { 't fàpàràpî̃u sì̀, à jàà ní́, à kààlì kùó, à kà kpá mî́ấ, à tiè mî́ắ, à pìyà' } \\
& \text { 'Bird got up, fetch water, went to farm, took guinea corn, chewed guinea corn, } \\
& \text { and was satisfied' } \\
& \text { so (bird, water), so (bird, farm), so (bird, corn) } \\
& \text { (FUS-SAN 1.6-1.11) }
\end{aligned}
$$

Example (6) illustrates that so can be translated into Chakali verbs expressing different meanings in the same sentence. The subject of the first verb is overt, i.e. saywara 'bird type' (Pterocles quadricinctus), and the subsequent verbs in the sentence share the same subject. The sentence shows a series of clauses introduced by the connective a 'and', which has the same form in Sigu and Chakali. The example (6) is intended to show that within a clause chain at least two different senses can be drawn, i.e. jaa 'fetch', kpa 'take', and kaalı 'go'.

\subsection{Discussion}

The various examples provided in $\$ 2.2$ demonstrate that so translates into semantically-varied Chakali verbs. The pre-theoretic groups existential, possession, motion, and transfer are used to cluster so's usage values into four sense groups. At the bottom of each example, a predicate-argument structure - i.e. so $(x, y)$ - contains the relation and the substantiation of the arguments.

The problem at this point is that while some of the readings of $\boldsymbol{s o}$ can clearly be separated from each other, others cannot. Having all usage values stored individually is not an ideal design: a 'full-storage' approach where each usage value is listed would not capture any generalisation. Furthermore, it is difficult to conceive of 
a single form with so many usage values in such a small lexicon, knowing that the learner has little exposure.

How does a consultant arrive at the meanings encoded in the corresponding Chakali verbs? According to Murphy (2010: 84), "[i]f a word has one sense that is general enough that it can be applied to many different things, then the word has a vague, or indeterminate sense". The question raised by the various translational units is whether they confirm different senses, or a single indeterminate one. Another related question is whether the sense groups proposed lack any logical or causal relation. In the next section, it is proposed that various representations and procedures are involved in narrowing down the proper interpretation of so, and that these are both linguistic and non-linguistic.

I am aware of the potential problems of this approach and a word of caution is in order here. With a lexical-translational heuristic to sense identification, the different senses in the object language are deduced from the corresponding expressions in the translation language. Matthewson (2004: 380) writes that translations should be seen as clues for semantic analysis, rather than as its result. This is what I had in mind in \$2.2. Ideally, meaning ought to be characterised language internally, coupled with a model of cognitive and/or linguistic categories describing meaning representation. This is what $\$ 3$ proposes.

\section{How does the meaning of so arise?}

How is $\boldsymbol{s} \boldsymbol{y}$ represented and how does the speaker-singer express and the heareraudience interpret a so-meaning? In this section I put forward a lexical concept for $\boldsymbol{s} \boldsymbol{s}$ with very limited core features and a series of constraints and strategies believed to force certain interpretations while excluding others. Let us call this narrowing, ${ }^{12}$ as the approach bears resemblance to that of recent studies in lexical pragmatics, constructionist frameworks, and discourse analysis.

One prerequisite of conceptual adjustment is the presence of a concept. The lexical concept represented in (7) is assumed. ${ }^{13}$

\footnotetext{
12 This notion is intended to be more inclusive than the notions of ad hoc concept (Carston 2002: 323), concept broadening/narrowing (Rubio-Fernández 2008), and on-line concept construction (Carston 2002: 320) documented in the pragmatic literature.

13 The attribute value matrix is a notational variant for the representation of feature structure. It does not presume any theoretical framework, although (7) is HPSG-inspired.
} 
(7) Lexical-conceptual representation for so

$$
\left[\begin{array}{ll}
\text { PHON } & s \jmath \\
\text { CAT } & v \\
\text { CONTENT } & {\left[\begin{array}{ll}
\text { ARG1 } & - \\
\text { ARG2 } & -
\end{array}\right]}
\end{array}\right]
$$

The core features of $\boldsymbol{s} \boldsymbol{s}$ are represented by the (PHON)onogical form /so/, which denotes a relation between ARG1 and ARG2. It is a relation that always has two roles to satisfy, but which is underspecified as to what sort of event relation holds between the arguments. These may be seen as the only inherent lexical-conceptual properties of the verb so.

Within this view, the lexical concept in (7) is an underspecified representation that gets adjusted to yield a more specific concept. The approach adopts frames that establish meaningful relations among participants, thereby constraining the meaning potential of so. It is shown in $\S 3.1$ that certain interpretations are determined by the denotations of the arguments and by the relation arguments have to one another at the sentential level. In addition to the immediate linguistic context, it is shown that nonimmediate and non-linguistic contexts play an important role in interpretation. In accordance, prior context, especially discourse structure and content, activates certain interpretations. This is discussed in $§ 3.2$. Since no other linguistic cues are available, pragmatic enrichment is necessary in order to explain certain meaning choices made by the consultants in the translation. Overall, the solution is based on interrelated mechanisms: an underspecified representation, a combinatorial system, semantic frames, pragmatic enrichment, prior context, and encyclopedic (world) knowledge.

\subsection{Who are the Participants and What Role Do They Play?}

It is well known that the immediate linguistic environment can constrain the construal of a word (Pustejovsky 1995). In keeping with this line of thinking, the likelihood that the denotations of certain arguments help to construe the meaning of so is taken into account. For instance, the subject of a transfer verb typically denotes an animate entity, so a constraint could be postulated to this effect. Another constraint could be that when the object of so denotes a location, then the yielding sentence is to be interpreted with either an existential-locative or motion meaning. An additional one could be that when the object of so denotes an alienable entity, either the transfer or possessive meaning should be interpreted.

(8) a. When $\boldsymbol{s} \boldsymbol{\partial}(x, y)$, if $\mathrm{x}=+$ ANIMINATE, transfer or possessive sense is more likely; 
b. When $\boldsymbol{s} \boldsymbol{\partial}(x, y)$, if $\mathrm{y}=+$ LOCATION, motion or existential-locative sense is more likely;

c. When $\boldsymbol{s o}(x, y)$, if $\mathrm{y}=+$ THING, transfer or possessive sense is more likely.

Since in principle the composition of a lexical item with another invites some meanings more than others, constraints such as the ones in (8), and possibly others, can narrow down the possible interpretation of so. One can easily imagine the necessity of the interplay of an animacy hierarchy, a prototypical location theory, etc. They are believed to be among the processes underlying the comprehension of so.

In association with argument denotation-based adjustment, another strategy proposed is that some of the meanings are structurally built. I adopt the notion of relational semantic structure (Fontanals 1999, 2002), an approach inspired by Bouchard (1995), which is thought of as a "syntactically relevant conceptual structure" (Fontanals 1999: 3) and a level of abstraction with "meaning present in the syntactic representations themselves" (Bouchard 1995: 16). One property of a relational semantic structure is that the various relations between arguments are established in a syntactically relevant conceptual structure, not in the lexical entry. Although I will not focus on syntax, I assume, like Bouchard, a certain homomorphous relationship between syntactic structure and semantic structure (see also Åfarli 2007). Viewed this way, a relational semantic structure will constrain the interpretation of so using structural location, that is, narrowing down the meaning of so would be based on where in the structure an argument is located in relation to another. This approach is well suited to deal with the multiple meanings which the verb so seem to convey.

To what degree can a relational semantic structure constrain the interpretation of so? It was shown in $\$ 2.2 .1$ and $\$ 2.2 .2$ that one interpretation of so was the existential-locative 'to be somewhere', and yet another was the possessive 'to have something'. Consider the structures of the fabricated examples in (9).

(9)

a.

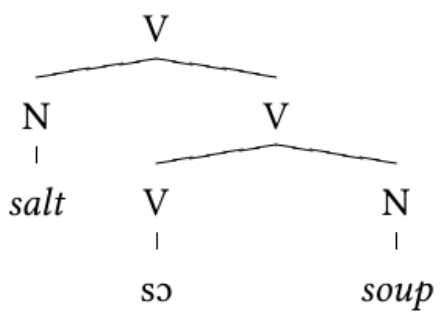

b.

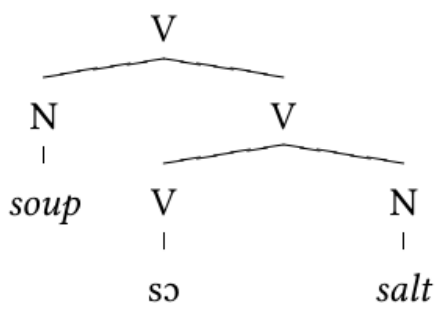


Even though the linear order of the existential-locative and the possessive sentence are reversed in (9), there are essential similarities between the two. ${ }^{14}$ The general observation is that an argument which functions as subject in the possessive sentence will function as an object with a locative role in the existential one. The reason why (9a) would not be interpreted *salt have soup but as salt is in soup could be that a hearer relies on a surface cue, i.e. linear order, and that both (9a) and (9b) map the arguments to the same relational semantic structure. This is in line with Baron \& Herslund (2001: 86) who argue that the exact meaning of a relation, in this case existential or possessive, depends "upon the semantic link between the subject and object". According to them, there are three different kinds of semantic link for a possessive sentence, which they identify as a denotative inclusion, i.e. "a relation where the denotation of the object noun is included in the denotation of the subject noun": a) when the object noun is part of a part-whole relationship, b) when the object noun denotes (part of) the possession of the subject noun, which is typically the case with an animate subject noun and non-relational object noun, and c) when the object noun constitutes a semantic feature of the subject noun so that the two form a chain of isotopic inclusion (Baron \& Herslund 2001: 87). ${ }^{15}$ It is when one of these three semantic links is established that a denotative inclusion is actualised, that is, when a possessive proposition of the form "X has $\mathrm{Y}$ " gets interpreted. Thus, what appears to be operating in (9) is a psychological process whereby encyclopedic knowledge affects the likelihood of certain construal (Clark, 1996). Like the semantic link of Baron \& Herslund in a) above, a particular piece of encyclopedic knowledge says that the soup/salt relationship consists of one having an ingredient (i.e. soup) and the other being an ingredient (i.e. salt). The relationship is a type of part-of relation, where one is an ingredient or component of another, but not vice-versa (see Winston et al. 1987: 425).

This exposition is intended to show that the conceptualisation of the arguments' realisation and their mutual relations play an important role in narrowing down the lexical concept. Conforming to the semantic links of Baron \& Herslund

\footnotetext{
14 In both sentences a proposition states the existence of something at some place. In fact, the observation that 'possession' has its origin in the primitive notion of 'existence' has long been presented in the literature. Benveniste, for instance, suggested that French avoir is an inverted être (Benveniste 1966; Bach 1967; Lyons 1967; Jung 2011; Freeze 2001; Wang \& Xu 2013). Bach (1967: 479-483) and Freeze (2001: 943) illustrate with data from Hindi, Tagalog, Finnish, Scots Gaelic, among others languages, the formal identification of existential and possessive verbs crosslinguistically, and both authors demonstrate that one can derive existential and possessive sentences from a common structure. Welmers (1974: 310) writes that "possession is a special case of location in Akan and Ewe".

15 If denotative inclusions are learned independent of language, alternatives to the one provided by in Baron \& Herslund (2001) can be imagined.
} 
(2001), these relations are meaningful and can be implemented in a syntacticallyrelevant semantic structure. One can imagine a common relational semantic structure as the one in $(10 a){ }^{16}$
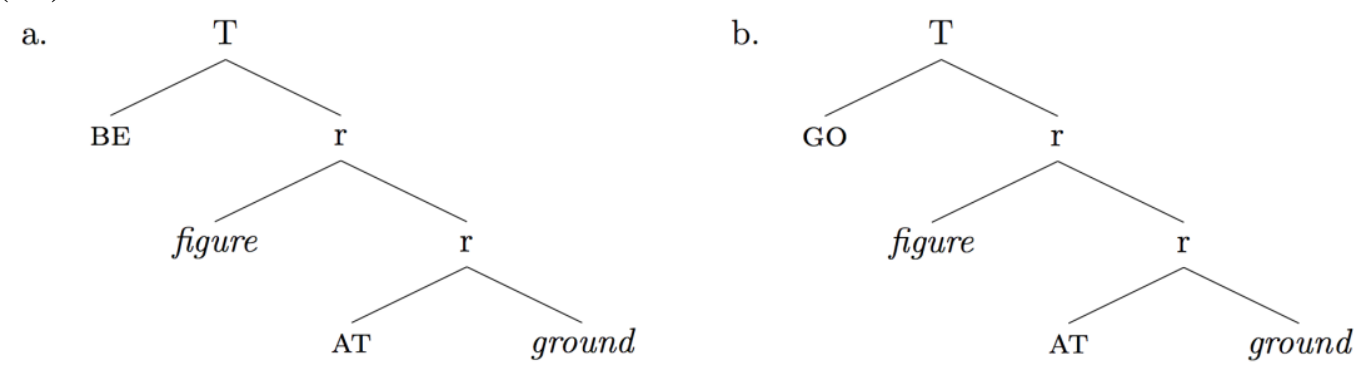

It is postulated that when one of the three denotative inclusions of Baron \& Herslund (2001) is triggered in the mind of the hearer, it activates a possessive reading. Otherwise a sentence predicated by so determines by default an existentiallocative reading. Put another way, since the object of $\mathbf{s o}$ in (9b) can be in a part-of relation with its subject, a possessive reading is derived. The relational semantic structure in (10a) can thus be seen as a common relational semantic structure where both the meaning of (9a) and (9b) can reside.

Although this suggestion covers two usage values of so, two others remain. First, recall that the motion sense of so, exemplified in $\S 2.2 .3$, is based on translations that use verbs like zov 'enter', wa liI 'come out', kaalı 'go', and tele 'reach'. In the examples provided, so co-occurs with individual locations in object position. Generally, what differentiates a motion verb from an existential-locative one is that the former involves a transition. This is reflected in Talmy's split of the category MOTION into motion and non-motion/static location (Talmy 2000). There are two analytic options for deriving the motion sense. The first is shown in (10b), where the relational semantic structures illustrate that an existential-locative and a motion sense of so differ only in terms of the nature of the relational element associated with the head of the $\mathrm{T}$ node. The relation between the figure and the ground is still a basic

\footnotetext{
16 Details on Relational Semantic Structure (RSS) can be read in Fontanals (1999); Fontanals \& Simón (1999); Fontanals (2002). In (10), $r$ stands for a "basic spatial relation". The relation is headed by AT, which "relates two non-relational elements into our cognitive space" (Fontanals 1999: 3), and a figure entity occupies the same relative position or area in space as a ground entity. The component standing for $T$ is to be interpreted as a transitional relation. Fontanals writes that $T$ is a semi-relation since 'is' has no specifier, but one complement. In some cases it can "be regarded as a transition between two complete relations $R$ and $r . "$
} 
spatial relation, the difference between the two frames is that (10a) reflects a static/non-motion relation while (10b) reflects a dynamic/motion relation.

The second analytic option is to say that, if the object of so is a location, context inference alone can explain why consultants used motion verbs in the Chakali translation. For instance, in (3a) and (3b), given that the objects of so are viewed as locations, a hearer needs to know the location of the agent prior to the event to establish whether so has to be interpreted as a static situation type or not. In (3c) and (3d) it is likely that the concept of 'road' activates more motion-like situations than static ones. Based on the corpus data and the one in (3) I am more inclined to prefer the second analytic option. So unless proven otherwise, the relational semantic structure in $(10 \mathrm{~b})$ is unavailable.

In \$2.2.4, the transfer sense of so was said to be found in serial verb constructions, but that it could also occur on its own, especially in clause chaining. It is believed that the interaction of two linguistic levels is responsible for the interpretation of the transfer sense. The first is a pragmatic enrichment where prior context allows for a physical action situation to be interpreted as opposed to a static situation: (4) and (6) are examples where the Chakali transfer verbs used in the translations suggest a pragmatically motivated interpretation. The second is a construction encoded in a relational semantic structure and deals specifically with so in the $\mathrm{v}_{1}$ position of a serial verb construction, as exemplified in (5). Similar to what is proposed in Lefebvre (1991), I assume that a serial verb construction in which so functions as the first verb, a causation component is introduced, such that a "causer causes a figure to VERB a ground'. ${ }^{17}$ This construction is common in many West African languages (Collins 1997; Ameka, 2006).

Notice that the CAUSE relational element in (11) is the head of a source relation $R$ which extends the frame of (10): it introduces a causer argument in the specifier of the relation $R$, which in turn takes a $T$ structure as complement. ${ }^{18}$

\footnotetext{
${ }^{17}$ Originator is another term employed for the same idea (Borer, 1994); other names for the same CAUSER role in the literature are antagonist, trajector, and instigator.

${ }^{18}$ In Fontanals (1999), $R$ "can be considered to be a source relation in the sense that its complement can come into existence by virtue of being immediately related with the superior $R$, whose specifier can be interpreted as the 'originator'."
} 
(11)

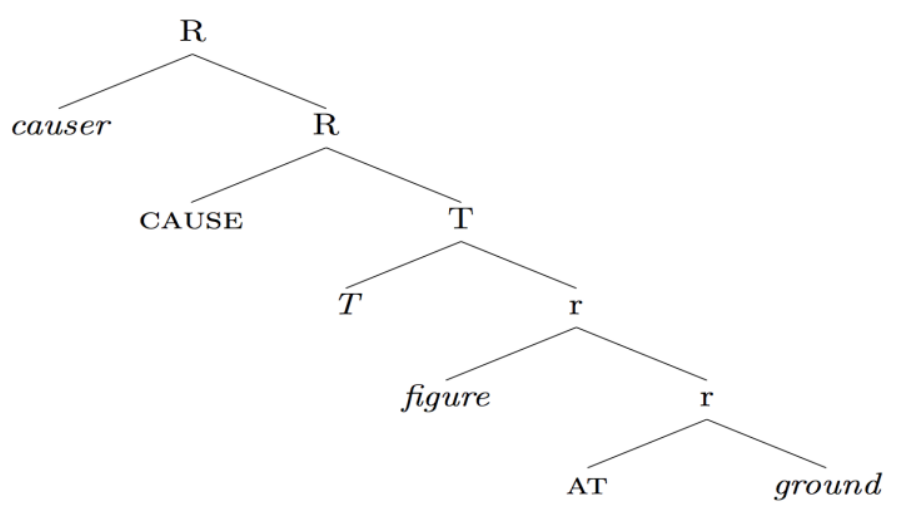

It may be expected that so is used to satisfy that verbal function in a manipulative serial verb construction; on the one hand, the causer is an animate entity and the ground a location. The figure always needs to be affected or manipulated, so it must be located by the causer in order to be affected. On the other hand, 'take' is a goal-based causative of 'have', and 'have' is the result state of 'take' (Viberg 2010). A construction like the one in (11), where the T structure and the external argument are related by so, a predicate otherwise capable of expressing existential-locative, possessive, and motion meanings, is a reasonable assumption.

Denotations of arguments and relational semantic structures together cannot distinguish all possible usage values. Apart from the so in $\mathbf{v}_{1}$ position of a serial verb construction and the transitive so, linear order and functional elements alone do not offer cues for disambiguation. For instance, in the fabricated sentences (12a) and (12c), an ambiguity cannot be avoided: in these two sentences there is no cue that can help in distinguishing whether there is transition or not. Also, a so-relation between a +HUMAN entity and a thing which can also function as location can be interpreted with an existential-locative, possessive, or motion meaning, i.e. John so be.at a house vs. John so have a house vs. John so go $_{\text {go }}$ a house.

(12) a. John so road.

' $\mathrm{J}$. is at the road'

b. John so money.

'J. has money'

c. John so road.

'J. goes to the road' 
d. John so money so road.

'J. puts money on the road'

To summarise, relational semantic structures like those offered in (10a) and (11) can narrow down the lexical-conceptual representation of so in (7) by specifying a situation type and structuring the arguments. Encyclopedic knowledge affects the likelihood of certain construals, which could be read from relational semantic structures. For instance, to account for $(12 \mathrm{a}-\mathrm{b})$ when the complement of the basic spatial relation AT is construed as a part-of, possession-of, telic role, included-in, or kin-of in relationship with the element of the specifier, a possessive sentence would be interpreted, otherwise an existential-locative reading is activated. Despite that, so can remain ambiguous and activation of specific meaning is influenced by nonsentential linguistic or non-linguistic context. In the next section we will look closely at how discourse structure and context inference are involved in concept narrowing.

\subsection{Discourse Structure and Context Inference}

The primary modality of Sigu is song. To my knowledge, the nature of Sigu discourse structure - its mode and organisation - has a partial parallel in the Novus Ordo, where the priest provides explanation in the language of the congregation after having first used Latin. "If lay people are attending, the priest may go to the pulpit and read the Epistle and the Gospel aloud in the vernacular language" (Trigilio et al. 2011: 92). Figure 1 illustrates the binary form of an idealised lead-and-chorus type of song. ${ }^{19}$ The first and last columns in the top box represent the order of the lead (A) and chorus (B). The middle column, showing the vertical sequence of numbers 4 (1) and 12 (3), presents a mapping between the 'measure' and the verse and chorus, i.e. 4 bell strikes or 1 group for a lead sequence, and 12 bell strikes or 3 group for a chorus.

Figure 1: Binary-strophic form: verse alternation contrasted with a recurring chorus and idealized verse-chorus-verse structure

\begin{tabular}{|lll|}
\hline $\mathbf{A}$ verse $_{A L}$ & $4(1)$ & Lead \\
$\mathbf{B}$ & $12(3)$ & Chorus \\
$\mathbf{A}$ verse $_{C L}$ & $4(1)$ & Lead \\
$\mathbf{B}$ & $12(3)$ & Chorus \\
\hline
\end{tabular}

\footnotetext{
19 'Idealised' because the length of the lead time can vary, with under-lap and over-lap between lead and chorus.
} 


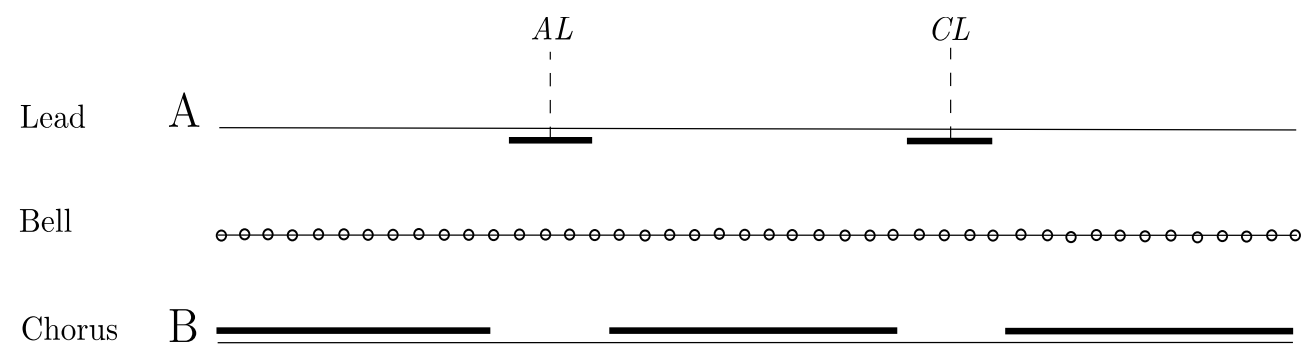

In Figure 1, $A L$ stands for alternate language and $C L$ for common language. It illustrates that while singing the lead can pass from one language to another. An observation gathered when attending and transcribing the verbal performances is that each language has a function. On the one hand, the alternate language is sacred; it is the language of the shrine, it has power, it is protected by protocols, it is not understood by everyone, it is an art form, etc. On the other hand, the common language is the everyday language, the language of the people. Choice of language is up to the singer himself, but it is usually the language with which he feels the audience will be more comfortable. It is Chakali if the performance is on Chakali land among Chakali, but as soon as various ethnicities are present, Waali is used.

In $\S 3.1$ it was argued that prior context is necessary in order to infer a motion sense. The same sort of inference was said to be involved in the transfer interpretation when so appears as the main predicate, because no cues can favour a transfer or a possessive interpretation. Disambiguation is highly dependent on prior context and decision hypotheses, which are based on information coded in at least two languages. This is what I call real-time translation (or consecutive interpretation), as opposed to the translations offered by the consultants after the performance.

The common language clarifies the message encoded in the alternate language. Since Sigu has a small lexicon and a near absence of functional elements, it is fair to say that any common language of the area is more expressive than Sigu, so that bringing some precision to the message may require a common language. A second reason can be that while the members of the audience may all be initiated into the spiritual group, they are not all equally familiar or acquainted with Sigu. The singer may therefore wish to clarify details of his narration for those who do not fully understand. Therefore the common language, consciously or unconsciously chosen, is the most appropriate language in their repertoire to express certain things given the linguistic background and proficiency of the audience. Consequently, in a Sigu performance, the non-immediate linguistic context is supplied by at least two different languages. But significantly, in the case of interpretation and ambiguity resolution the 
common language helps contextualize meaning. The short excerpts in (13) provide concrete examples.

(13) a. Sunguruma: 00:02:52.60 - 00:03:04.18

$A_{A L}$ : kùnú gbàmpálèrìm śs $n$ dānI

lit. father war-garment $\underline{\underline{s}} \underline{\mathrm{g}}$ me

$\mathrm{A}_{C L}$ : 'dí ù néná lááltāyātā tìn né dớó ò hàbùò ní kéǹ'

'That his father war garment is on his back'

b. Tanihige: 00:06:15.15-00:06:20.85

$\mathrm{A}_{A L}$ : náátárá ní sò wògớwògú

lit.(if) person $\underline{\text { so }}$ money

$\mathrm{A}_{C L}$ : 'háálì dī nár kpágá mòlébíé'

'Even if someone has money'

The lyrics in (13a) are from a song about a tortoise boasting about his shell and trying to challenge everyone, especially a bird. The shell is referred to here as 'father's war garment'. In (13a) the singer chose to change his narrative point of view: the line in Sigu $\left(\mathrm{A}_{A L}\right)$ is revealed through the first-person (i.e. the narrator is also a character) but the line in Chakali $\left(\mathrm{A}_{C L}\right)$ is revealed through the third-person. The singer uses the common language and picks up the proposition of the preceding verse, expands upon and clarifies it. Based on what has been proposed in $\$ 3.1$, if the first person pronoun is treated as a location, so could be interpreted with an existentiallocative or a motion sense. Using the common language in the performance itself, the singer narrows down the meaning of so by translating it with the Chakali existentiallocative copula doo. Similarly, (13b) illustrates a case where so could receive a possessive or transfer reading in the Sigu verse, but the singer expresses the proposition intended with the possessive verb kpaga in the common language.

Hence the use of the common language may be thought of as a strategy to make explicit in order to reproduce what is obvious using a common language, but less straightforward using the alternate language. However, it would be wrong to think of this transition from one language to the other as being constant. Therefore the audience cannot rely on a systematic and continuous translation of Sigu into a common language.

The physical context must be considered as a potential constraint on the interpretation of so. One aspect of physical context is gesture: the singer is also a narrator who expresses information in gestures, either supported or not by words. So arm and hand gestures can narrow down interpretations as well. For instance, iconic gestures representing a transition (i.e. manner of motion, upward or downward path, etc.) will look different compared to those representing stative eventualities. Gestures 
must have limited impact, however, since songs are performed in partial darkness, under the rays of the moon. More importantly, for this paper, the translators had no access to visual data. Another aspect of physical context is the one established in a narrative. It is only when a hearer shares the world of the singer that he or she is able to assign the meaning(s) intended efficiently. For instance, because so can predicate over many types of individuals (i.e. as shown in $\$ 2.2 .1$ to 2.2 .3 ), a set of assumptions about the narrated world is needed to resolve deictic expressions, and this is often cued by the imagined physical context described in a narrative. Thus, a narrative description builds up in the discourse; the hearer draws physical context data from the narrative description, and is able to assign status to deictic expressions which in turn may allow certain $\boldsymbol{s} \boldsymbol{o}$ interpretations while excluding others.

A speaker-singer and hearer-audience must draw from the discourse structure and content and narrated settings. A language learned with little exposure and practice and with fewer lexical and grammatical coding strategies in comparison with the languages of the area is likely to rely more extensively on pragmatic enrichment and non-conventional means of communication. A similar argument is made for pidgins in Mühlhäusler (1986: 137-138). Real-time translation in songs, domain specific knowledge of details of particular Sigu events (e.g. whose death, location, cause and manner of death; who sacrifices; what has he or she brought to the shrine; etc.), and the narrated universe can all be involved in establishing the specific so-meaning. Obviously more work is needed on the role of pragmatic enrichment and nonconventional means of communication in Sigu performance.

\section{Conclusion}

The main methodological obstacle lies in the nature of Sigu. Its investigative potential does not really allow the use of elicitation and other field linguistic methods. Yet, even if Sigu could be accessed and studied like a 'natural' language, it is important to remember that the production and interpretation of so by the singers and audience respectively are settled simultaneously or consecutively in singing performances, not in conversation. Thus a first analysis based on the texts of songs and their translation is deemed appropriate and representative. Another potential methodological drawback is the fact that the bulk of the translations are the product of two individuals, so that the choice of Chakali words in the exercise and their representativeness may not be optimal. Nevertheless, whatever selection a translator makes, it always seems to appear within the proposed sense groups. This is borne out in the performance itself, and was brought up in $\$ 3.2$ under the notion of real-time translation.

To recapitulate, the analysis in $\S 3$ assumes an underspecified lexicalconceptual representation as a generic level accessible to a variety of meaning 
intentions. Its combinability potential is always two, i.e. ARG1 and ARG2. The labels on the branches in (14) stand for the interpretation strategies which were described as responsible for narrowing down the underspecified lexical concept.

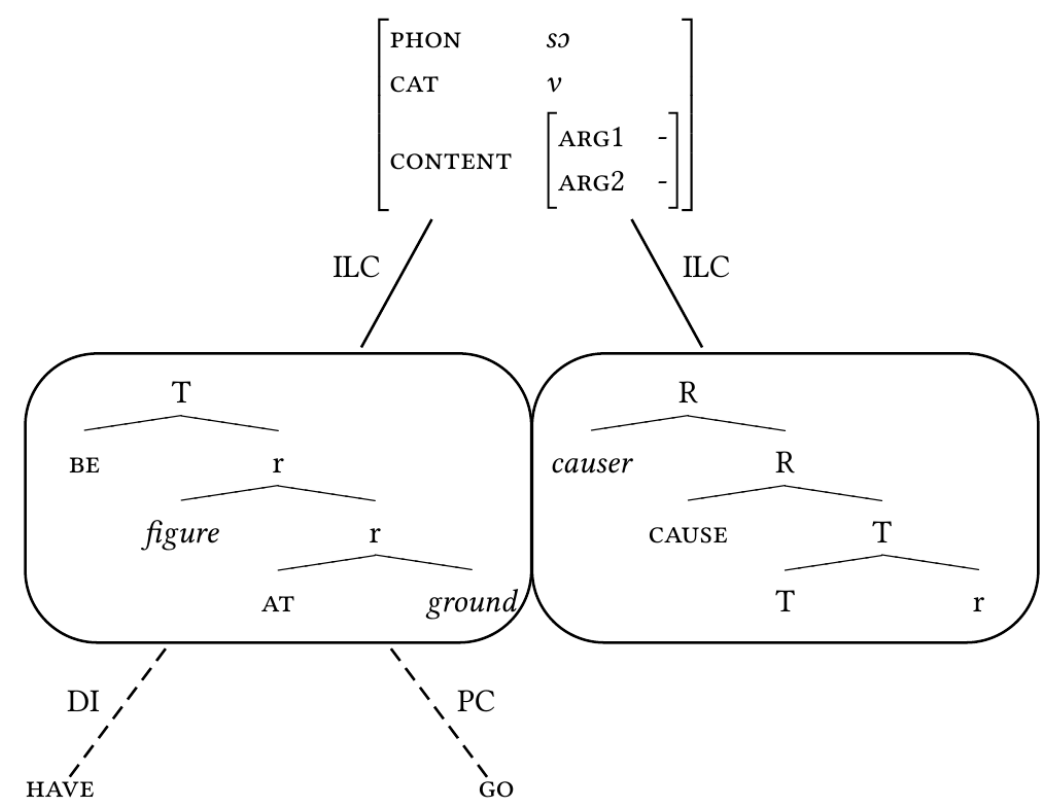

The BE-transitional relational semantic structure hierarchizes the individuals filling the place holders ARG1 and ARG2, and establishes a basic spatial relation between a figure and a ground. One of the cues exploited is found in the immediate linguistic context (ILC): the object of the verb so must be a potential location to locate the participant interpreted as the figure. The hypothesis is that the default interpretation of transitive so is a existential-locative meaning. A denotative inclusion (DI) is actualised when the denotation of the object noun can be conceived as being included in the denotation of the subject noun. Triggering a denotative inclusion requires encyclopedic knowledge, which is normally argued to be fixed by experience (see also Idealized Cultural Models in Lakoff 1987). The possessive meaning was said to be accessible only if a denotative inclusion could be established. The underspecified lexical concept has no inherent transitional component but acquires one from context. For a sentence to be interpreted as a motion event rather than a nonmotion one, it was suggested that aspects of previous context (PC) are needed to allow for the enrichment of the transitional component. None of the information available in the immediate linguistic context can act as clue in interpreting a motion or 
non-motion event. If the phases of a transfer schema are viewed as being initiated with a HAVE perspective (Wildgen 2005: 416), then one may question the interest of having the CAUSE component directly linked to the underspecified lexical concept instead of having it derived from the HAVE component. First, as I argued in this article, the manipulative serial verb construction in Chakali (i.e. $x$ CAUSE $y$ verb $z$ ) is a pervasive and omnipresent linguistic construction which must be used by the speakers of the alternate language. Secondly, the construction is unique because it is the only $\left[\begin{array}{lllll}N P & v_{1} & N P & v_{2} & N P\end{array}\right]$-construction found in the Sigu corpus, and its first verb is exclusively so. These are the motives for my proposal to classify the relational semantic structure of manipulative serial verb construction as a meaning representation accessible, and not derived from HAVE. Notice that the place holders for ARG1 and ARG2 are satisfied by a causer and a transitional relation, the former being an entity and the latter a relational event. That is not claiming that the meaning of the first verb of a manipulative serial verb construction and a possessive meaning are not related conceptually (even perhaps diachronically in Chakali).

The subjective and pre-theoretical eventuality group existential, possessive, motion and transfer are analysed as two frame senses, a transitive BE-transitional and a manipulative serial verb construction, the former being further narrowed down by denotative inclusion and previous context. The use of prior and physical contexts was argued to be sometimes unavoidable and sometimes helpful for interpreting expressions and relations. A singer can clarify his story using a common language, therefore translates the predications of the Sigu sentences with no other alternative than more precise predicates available in the common language. In general, the proposed approach is very flexible as it can, in principle, make use of many levels of linguistic and non-linguistic processes, thus relying less on a list of memorised senses for a single form.

Finally, in considering the validity of theories such as relexifixation/relabeling (Muysken 1981; Lefebvre 1988; Wittman \& Fournier 1996; Lefebvre 2014), paralexification (Mous 2001) and Full Transfer/Full Access (Schwartz \& Sprouse 1996) to interpret lexically-manipulated language data, I asked how lexical features of the L1's verbal lexemes are copied into the lexically-manipulated language. Although the question of mapping is not addressed specifically in this article, there is a general tendency to assume that vocabulary replacement is equivalent to a one-to-one mapping of syntactic and semantic features plus relabeling (Lefebvre 2014: 10, but see Dixon 1971). The article suggests the idea that a lexically-manipulated language may not necessarily map one-to-one to their L1 in vocabulary replacement. Instead the various usage values of so either suggest a many-to-one mapping between Chakali and Sigu, or a different view on the lexical semantics of verbs altogether. In particular, it exposes a deficiency of vocabulary replacement theories as models for 
linguistic manipulation design and genesis by showing that the lexical organisation of a lexically-manipulated language may not necessarily be found in the speakers' L1. If several verbal lexical items are copied onto a single one in the alternate language and then relabeled, the details of the operation which modulates meanings in a many-toone fashion are not made explicit in any of the theories mentioned. Although I have proposed an analysis where so can accommodate meanings which initially seemed hard to unify, to my knowledge no other languages of the area possesses a form capable of expressing existential-locative, possessive, motion, and transfer meanings in one and the same word. Therefore, the lexical concept $\mathbf{s o}$ and the usage values it is capable of expressing challenge a relexified/relabeled analysis of lexicallymanipulated languages. It would be interesting to find a language that encodes and processes linguistic knowledge similarly in order to better understand so in Sigu and to shed light on lexical manipulation.

\section{References}

Åfarli, Tor Anders, 2007. Do verbs have argument structure? In Giorgos Spathas, Eric J. Reuland and Tanmoy Bhattacharya, eds., Argument Structure, Linguistik Aktuell/Linguistics Today 108: 1-16. John Benjamins Publishing Company.

Amberber, Mengistu, 1995. Functional verbs in predicate formation: event-type hierarchy and grammaticization. In Proceedings of the Twenty-First Annual Meeting of the Berkeley Linguistics Society: General Session and Parasession on Historical Issues in Sociolinguistics/Social Issues in Historical Linguistics, pp. 1-11. Berkeley CA.

Ameka, Felix K. 2006. Ewe serial verb constructions in their grammatical context. In A. Y. Aikhenvald and R. M. W. Dixon, eds., Serial verb constructions: A cross linguistic typology. Pp. 124-141. Oxford: Oxford University Press.

Ameka, Felix K. and James Essegbey, 2006. Elements of the grammar of space in Ewe. In Stephen C. Levinson and David Wilkins, eds., Grammars of Space. Language, Culture and Cognition. Cambridge: Cambridge University Press.

Bach, Emmon, 1967. Have and be in English syntax. Language 43: 462-485.

Bagemihl, Bruce, 1996. Language games and related areas. In John A. Goldsmith, ed., The Handbook of Phonological Theory. Chap. 23, pp. 697-712. Cambridge: Blackwell.

Bagemihl, Bruce, 1988. Alternate Phonologies and Morphologies. PhD Dissertation, University of British Columbia.

Baron, Irène and Michael Herslund, 2001. Semantics of the verb HAVE. In Irène Baron, Michael Herslund and Finn Sørensen, eds., Dimensions of Possession, Chapter 5. Amsterdam: John Benjamins Publishing Company.

Benveniste, Émile, 1966. Problèmes de linguistique générale. Bibliothèque des sciences humaines. Paris: Gallimard. 
Borer, Hagit., 1994. The projection of arguments. University of Massachussetts Occasional Papers in Linguistics 17.

Bouchard, Denis, 1995. The Semantics of Syntax: A Minimalist Approach to Grammar. Chicago: University of Chicago Press.

Brindle, Jonathan Allen, 2011. Aspects of the Chakali language. Ph.D thesis, Norges TekniskNaturvitenskapelige Universitet (NTNU). Trondheim

Brindle, Jonathan Allen and Samuel Awinkene Atintono, 2012. A comparative study of topological relation markers in two Gur languages: Gurene and Chakali. In Selected Proceedings of the 42nd Annual Conference on African Linguistics: African Languages in Context. Somerville MA: Cascadilla Proceedings Project.

Carston, Robyn, 2002. Thoughts and Utterances: The Pragmatics of Explicit Communication. Oxford: Blackwell.

Clark, H. H., 1996. Using Language. Cambridge: Cambridge University Press.

Collins, Chris, 1997. Argument sharing in serial verb constructions. Linguistic Inquiry 28: 461-497.

Demolin, D., 1991. L'analyse des segments, de la syllabe et des tons dans un jeu de langage Mangbetu. Langages 101: 30-50.

Dixon, R. M. W., 1971. A method of semantic description. In D. D. Stenberg and L. A. Jakobovits, eds., Semantics: An interdisciplinary reader in philosophy, linguistics and psychology, pp. 436-471. Cambridge: Cambridge University Press..

Fontanals, Jaume Mateu, 2002. Argument structure : relational construal at the syntaxsemantics interface: Universitat Autònoma de Barcelona dissertation.

Fontanals, Jaume Mateu, 1999. Universals of semantic construal for lexical syntactic relations. In GLOW Workshop on Sources of Universals, Potsdam.

Fontanals, Jaume Mateu and Laia Amadas Simón, 1999. Extended argument structure: progressive as unaccusative. Catalan Working Papers in Linguistics 7.

Freeze, Ray, 2001. Existential constructions. In Martin Haspelmath, ed., Language Typology and Language Universals / Sprachtypologie und Sprachliche Universalien / La Typologie des Langues et les Universaux Linguistiques. Pp. 941-953. Handbooks of Linguistics and Communication Science. Berlin and New York: W. de Gruyter.

Hombert, J. M., 1986. Word games: some implications for analysis of tone and other phonological constructs. In J. J. Ohala and J. J. Jaeger, eds., Experimental Phonology, pp. 175-185. London: Academic Press.

Jung, Hakyung, 2011. Syntax of the Be-Possessive: Parametric Variation and Surface Diversities. Amsterdam and Philadelphia: John Benjamins Publishing Company.

Lakoff, George, 1987. Women, Fire, and Dangerous Things: What Categories Reveal About the Mind. Chicago: University of Chicago Press.

Laycock, D., 1972. Towards a typology of ludlings, or play languages. Linguistic Communications, Working Papers of the Linguistic Society of Australia 6: 61-113. 
Le Moal, Guy, 1980. Les Bobo: nature et fonction des masques (Travaux et documents de l'ORSTOM 121). Paris: ORSTOM.

Lefebvre, Claire, 2014. Relabeling in Language Genesis. New York: Oxford University Press.

Lefebvre, Claire, 1991. Take serial verb construction in Fon. In Serial Verbs: Grammatical, Comparative, and Cognitive Approaches, pp. 37-78. Studies in the Sciences of Language series. Amsterdam: John Benjamins Publishing Company.

Lefebvre, Claire, 1988. Creole Genesis and the Acquisition of Grammar: The case of Haitian Creole. Cambridge: Cambridge University Press.

Leiris, Michel, 1948. La langue secrète des Dogon de Sanga. Paris: Institut d'Ethnologie.

Lyons, John, 1967. A note on possessive, existential and locative sentences. Foundations of Language 3.4: 390-396.

Matthewson, Lisa, 2004. On the methodology of semantic fieldwork. International Journal of American Linguistics 70.4: 369-415.

McCarthy, John J., 1991. L'infixation réduplicative dans les langages secrets. Langages $25.101: 11-29$.

Moñino, Yves, 1991. Les langues spéciales sont-elles des langues? La notion de pseudolangue à travers l'exemple d'une 'langue d'initiation' d'Afrique Centrale. Langage et société 56: 5-20.

Mous, Maarten, 2003. The linguistic properties of lexical manipulation and its relevance for Ma'á. In Yaron Matras and Peter Bakker, eds., The Mixed Language Debate, Theoretical and Empirical Advances. Pp. 209-235. Berlin: Walter de Gruyter.

Mous, Maarten. 2001. Paralexification in language intertwining. In Norval Smith and Tonjes Veenstra, eds., Creolization and Contact, pp. 113-123. Amsterdam: John Benjamins.

Mühlhäusler, P., 1986. Pidgin and Creole Linguistics. Oxford: Basil Blackwell.

Murphy, L., 2010. Lexical Meaning. Cambridge Textbooks in Linguistics. Cambridge: Cambridge University Press.

Muysken, Pieter, 1981. Halfway between Quechua and Spanish: the case for relexification. In Arnold Highfield and Albert Valdman, eds., Historicity and Variation in Creole Studies, pp.52-78. Ann Arbor: Karoma.

Pustejovsky, James, 1995. The Generative Lexicon. Cambridge, MA: MIT Press.

Rubio-Fernández, Paula, 2008. Concept narrowing: the role of context-independent information in concepts. Journal of Semantics 25: 381-409.

Schwartz, Bonnie D. and Rex A. Sprouse, 1996. L2 cognitive states and the Full Transfer/Full Access model. Second Language Research 12.1: 40-72.

Talmy, Leonard, 2000. Toward a Cognitive Semantics, vol. 1. Cambridge, MA: MIT Press.

Trigilio, J., K. Brighenti and M. J. Cafone, 2011. Catholic Mass for Dummies. Wiley.

Viberg, Åke, 2010. Basic verbs of possession. CogniTextes 4. Retrieved from http://cognitextes.revues.org/308\#text, Oct. 16, 2015. 
Brindle: Multiple Senses of so in Sigu

Wang, Yong and Jie Xu. 2013. A systemic typology of existential and possessive constructions. Functions of Language 20.1: 1-30.

Welmers, W. E., 1974. African Language Structures. University of California Press.

Wildgen, Wolfgang, 2005. Catastrophe theoretical models in semantics. Internationales Handbuch der Quantitativen Linguistik pp. 410-422. Berlin: de Gruyter.

Winston, Morton E., Roger Chaffin and Douglas Herrmann, 1987. A taxonomy of part-whole relations. Cognitive Science 11.4: 417-444.

Wittman, Henri and Robert Fournier, 1996. Contraintes sur la relexification: les limites imposées dans le cadre de la théorie minimaliste. Revue québécoise de linguistique 13: $245-280$. 